\title{
Transposon mediated co-integration and co- expression of transgenes in CHO-DG44 cells
}

\author{
Sowmya Balasubramanian, Mattia Matasci, Lucia Baldi, David L Hacker, Florian M Wurm \\ From 22nd European Society for Animal Cell Technology (ESACT) Meeting on Cell Based Technologies \\ Vienna, Austria. 15-18 May 2011
}

\begin{abstract}
Background
Transposon systems mediate stable integration of exogenous DNA elements into a host cell genome, and have been successfully used in mammalian cells for the generation of stable cell lines. The piggyBac (PB) transposon system has been shown to have several advantages over the other transposon system available [1-3]. It has also been shown to generate stable cell lines at significantly higher frequency than the conventional transfections [3]. Here, we investigated the efficiency of the piggyBac (PB) transposon to facilitate the co-expression of multiple artificial transposons, each bearing a single transgene and the puromycin resistance gene for selection. Green fluorescent protein (eGFP), red fluorescent protein (mKate), and a human IgG1 antibody were used as model proteins [4]. The effect of the stringency of selection on pool productivity was determined with increasing concentrations of puromycin. The duration of selection necessary for the generation of recombinant cell pools was also tested by selecting for a period of either 5 or 10 days.
\end{abstract}

\section{Materials and methods CHO-DG44 transfection}

Cells were transfected using linear $25 \mathrm{kDa}$ polyethylenimine (PEI) (Polysciences, Eppenheim, Germany). All the transfections are done in a final volume of $10 \mathrm{~mL}$. Transfected cultures were incubated at $37^{\circ} \mathrm{C}$ in $5 \% \mathrm{CO}_{2}$ and $85 \%$ humidity with agitation at $180 \mathrm{rpm}$. The ratio of plasmid coding for Gene of Interest (GOI) to the plasmid coding for the transposase was kept constant at 9:1.

\footnotetext{
* Correspondence: florian.wurm@epfl.ch

Laboratory for Cellular Biotechnology (LBTC), Faculty of Life Sciences, École Polytechnique Fédérale de Lausanne CH-1015 Lausanne, Switzerland
} Full list of author information is available at the end of the article

\section{Generation of pools and clones}

For the generation of stable pools, two days post transfection the cells were seeded at a density of $5 \times 10^{5}$ cells $/ \mathrm{mL}$ in ProCHO5 and puromycin. The cells were placed under selection pressure for 5 or 10 days. In case of a 10 day selection period, the puromycin concentration in the cultures was replenished on day 7 post transfection by seeding at a density of $5 \times 10^{5}$ cells $/ \mathrm{mL}$ in fresh ProCHO5 with puromycin. For productivity analysis the cells were seeded at a density of $3 \times 10^{5}$ cells $/ \mathrm{mL}$ and analyzed at day four.

Stable clones were generated by limiting dilution of the pools. The productivity of the clones was analyzed after five days of culture.

\section{Analyses}

A Guava EasyCyte microcapillary flow cytometer (Millipore) with excitation and emission wavelengths of 488 and $532 \mathrm{~nm}$, respectively, was used to measure EGFPspecific fluorescence. The IgG concentration in the culture medium was determined by sandwich ELISA as previously described [4].

\section{Results}

PB Transposition significantly enhances co-expression of multiple genes from stable pools compared to standard transfection

Cells were co-transfected with three artificial transposons namely, eGFP and the heavy and light chains of a human IgG1 antibody along with the plasmid coding for the transposase. Cell populations recovered after selection showed $30 \%$ of GFP positive cells for standard transfections, whereas for pools generated by PB transposition, the percentage of cells producing GFP was up to $80 \%$, which represent a 2.5 fold improvement (Fig. 1A). IgG1 productivity up to $120 \mathrm{mg} / \mathrm{L}$ was achieved using transposition, whereas in standard transfections 


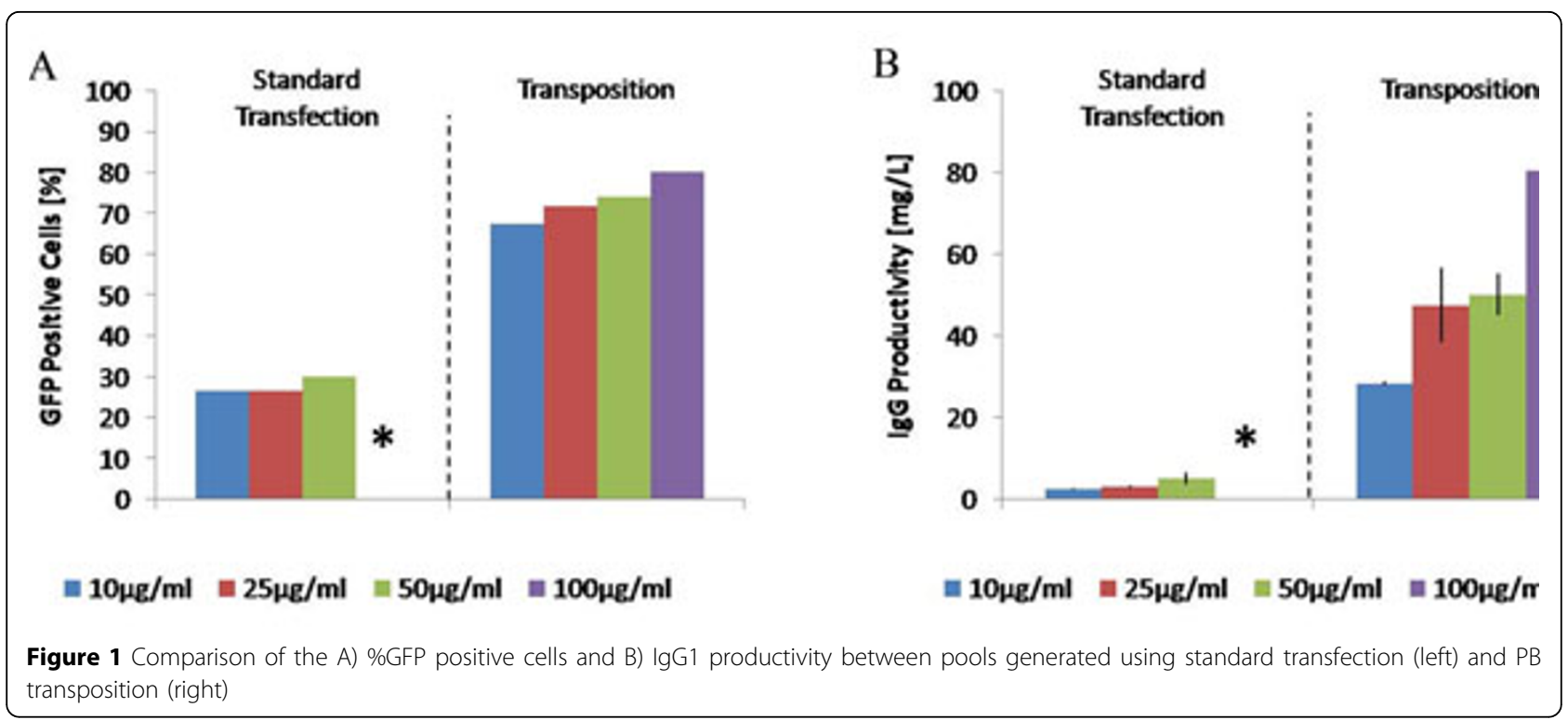

the highest titers obtained were only $5 \mathrm{mg} / \mathrm{L}$, corresponding to a 24 fold improvement (Fig. 1B).

No significant differences were observed in the percentage of GFP positive cells and IgG productivity in cell pools generated by transposition with 5 or 10 days of selection. However, increased IgG productivity and \% GFP-positive cells were observed with 10 days of selection in case of standard transfection (data not shown). This shows that a longer duration of selection pressure is necessary to generate pools by standard transfections compared to transposition. Furthermore, increased antibody productivity was observed with increasing puromycin concentration (Fig. 1).

PB transposition strongly improved clonal productivity Four different plasmids coding for (1) EGFP, (2) mKATE, (3) the light and (4) heavy chain genes of a human IgG1 antibody. Clones for both the standard and the transposition-based transfections were generated by limiting dilution of the cell pools after selection for 10 days. The IgG productivities of 65 clones of each standard transfection and transposition were analyzed. About $96 \%$ of the clones generated by the standard transfection were found to be low-producing. However, more than $40 \%$ of clones generated by transposition

Table 1 Distribution of clones based on their IgG productivity

\begin{tabular}{ccc}
\hline Productivity Range & Standard Transfection & Transposition \\
\hline$<\mathbf{2 0} \mathbf{~ m g / L}$ & $96 \%$ & $57 \%$ \\
$\mathbf{2 0 - 6 0} \mathbf{~ m g / L}$ & $4 \%$ & $30 \%$ \\
$>\mathbf{6 0} \mathbf{~ m g / L}$ & $0 \%$ & $13 \%$ \\
\hline
\end{tabular}

produced more than $20 \mathrm{mg} / \mathrm{L}$ and about $12 \%$ of the clones were high-producers (Table 1 ).

\section{Conclusions}

Based on the above results we conclude that the piggy$B a c$ transposon system provides an efficient method for the co-integration of multiple genes. The use of the $\mathrm{PB}$ transposon system for the co-integration of multiple genes generates a higher frequency of high-producing clones than standard transfection. The GFP-expressing cell population was larger and the volumetric antibody productivity of the pools were higher with higher stringency of selection. A selection period with puromycin of only 5 days was sufficient for the generation of pools from transposon mediated transfection.

\section{Acknowledgments}

This work has been supported in part by the CTI Innovation Promotion Agency of the Swiss Federal Department of Economic Affairs ( $n$. 10203.1PFLS-LS), in collaboration with the company ExcellGene SA in Monthey, Switzerland.

\section{Published: 22 November 2011}

\section{References}

1. Kahlig KM, Saridey AK, Kaja A, Daniels MA, George AL Jr, Wilson MH: Multiplexed transposon-mediated stable gene transfer in human cells. Proc Natl Acad of Sci USA 2010, 107(4):1343-8.

2. Wilson MH, Coates CJ, George AL Jr: PiggyBac Transposon-mediated Gene Transfer in Human Cells. Molecular Therapy 2007, 15:139-145.

3. Matasci M, Baldi L, Hacker DL, Wurm FM: The PiggyBac Transposon Enhances the Frequency of CHO Stable Cell Line Generation and Yields Recombinant Lines with Superior Productivity and Stability. Biotechnol Bioeng 2011, doi: 10.1002/bit.23167.

4. Meissner P, Pick H, Kulangara A, Chatellard P, Friedrich K, Wurm FM: Transient gene expression: recombinant protein production with suspension-adapted HEK293-EBNA cells. Biotechnol Bioeng 2001, 75:197-203. 
doi:10.1186/1753-6561-5-S8-P32

Cite this article as: Balasubramanian et al:: Transposon mediated cointegration and co-expression of transgenes in CHO-DG44 cells. BMC Proceedings 2011 5(Suppl 8):P32.

Submit your next manuscript to BioMed Central and take full advantage of:

- Convenient online submission

- Thorough peer review

- No space constraints or color figure charges

- Immediate publication on acceptance

- Inclusion in PubMed, CAS, Scopus and Google Scholar

- Research which is freely available for redistribution

Submit your manuscript at www.biomedcentral.com/submit

C) BioMed Central 